\title{
Visão Baseada em Recursos da Empresa, Inteli- gência Competitiva e Balanced Scorecard: em busca da vantagem competitiva sustentável
}

\author{
Paulo Henrique de Oliveira ${ }^{1}$ \\ Carlos Alberto Gonçalves ${ }^{2}$ \\ Edmar Aderson Mendes de Paula
}

\section{Resumo}

Este artigo apresenta um modelo teórico que integra três importantes temas relacionados à Teoria da Estratégia na atualidade - Visão Baseada em Recursos da empresa (VBR), Inteligência Competitiva (IC) e Balanced Scorecard (BSC) nos planos da formulação e implementação estratégicas. Esses temas têm sido apresentados em publicações de pesquisadores no campo da estratégia com alcance nas dimensões de conceito e de processo. De um lado, a VBR como ênfase inside out nos remete a avaliar o que somos e o que temos, em relação a condições de aperfeiçoamento, para alcançar resultados superiores. O modelo IC nos remete à condição de ligação de outside in e inside out para nos posicionarmos na linha de interface das organizações. O BSC nos orienta sobre a condição de atender a poucas dimensões e processos. Este trabalho discute, também, como essa integração pode apoiar as empresas a conquistarem vantagens competitivas nos mercados em que atuam ao longo do tempo.

Palavras-chave: Visão Baseada em Recursos. Inteligência Competitiva. Balanced Scorecard. Abordagem Integrada.

\footnotetext{
${ }^{1}$ Doutorando em Administração no Centro de Pós-Graduação e Pesquisas em Administração - CEPEAD/UFMG. Mestre em Engenharia de Produção pelo Instituto Federal de Minas Gerais - IFMG. Endereço:

Av. Antônio Carlos, 6627 - Pampulha - Belo Horizonte-MG - Brasil. CEP: 31270-901. E-mail: phdo@cepead.face.ufmg.br.

${ }^{2}$ Doutor em Administração pelo Centro de Pós-Graduação e Pesquisas em Administração - CEPEAD/UFMG. Endereço: Av. Antônio Carlos, 6627

-Pampulha-Belo Horizonte -MG - Brasil. CEP: 31270-901. E-mail: carlos@face.ufmg.br.

${ }^{3}$ Mestre em Engenharia Mecânica, Faculdade Pitágoras. Endereço: Av. Juscelino Kubitscheck, 229 - Centro - Betim - MG - Brasil. E-mail:edmarp@pitagoras.com.br.

Artigo recebido em: 10/04/2010. Aceito em: 12/08/2010. Membro do Corpo Editorial Científico responsável pelo processo editorial: Martinho Isnard Ribeiro de Almeida.
} 


\section{Introdução}

Pesquisas recentes têm evidenciado o aumento da complexidade e dinamicidade do ambiente de negócios (PORTER, 1980; 1989; PRAHALAD; HAMEL, 1990; D'AVENI, 1995; HITT; IRELAND; HOSKISSON, 2003; BARNEY; HESTERLY, 2007). Para muitos desses autores, entra-se em uma era determinada por incertezas crescentes e hipercompetição, em que vantagens competitivas são rapidamente imitadas e/ou superadas pelos concorrentes. Para sobreviver e prosperar, nesses ambientes de acirrada competição, torna-se necessário que as empresas sejam capazes de se ajustarem com maior rapidez e eficácia às crescentes ameaças e oportunidades impostas por seus ambientes em transformação (OLIVEIRA; ALMEIDA; LACERDA, 2007).

Assim, fatores como flexibilidade, rapidez e inovação contínua em bens e serviços oferecidos aos mercados consumidores podem determinar o sucesso ou o fracasso de uma empresa no mercado em que atua ao longo do tempo.

Com o aumento da incerteza percebida nos ambientes de negócios, temas como monitoramento ambiental, gestão da informação e do conhecimento, inteligência competitiva, capacidades dinâmicas, estratégia empresarial e competências essenciais, entre outros, têm assumido papel de destaque na medida em que permitem aos altos executivos tomarem decisões estratégicas mais eficazes e orientadas para a obtenção de vantagens competitivas sustentáveis e consequentes retornos financeiros acima da média nos setores em que as empresas atuam. E é nesse contexto que o Balanced Scorecard (BSC) também assume papel de destaque como sistema de gerenciamento estratégico capaz de avaliar o desempenho de uma estratégia através da análise de quatro perspectivas principais: financeiras, dos clientes, dos processos internos e do aprendizado e crescimento empresarial (KAPLAN; NORTON, 1997).

Nessa perspectiva, o presente artigo, a partir de uma pesquisa teórica, analisa as relações de dependência informacionais existentes entre a Inteligência Competitiva (IC) e o Balanced Scorecard (BSC), discute a importância dos mesmos para a obtenção de Vantagens Competitivas Sustentáveis (VCS), no contexto da Visão Baseada em Recursos da empresa (VBR) em inglês $R B V$ (Resource-based View - RBV), e propõe um modelo teórico para demonstrar o relacionamento sistêmico entre tais processos organizacionais.

Estruturalmente este artigo está assim organizado: na primeira parte são apresentados alguns conceitos sobre vantagem competitiva e o desafio da 
empresa em mantê-la por longos períodos de tempo (sustentabilidade). Na segunda parte são analisados os fundamentos básicos da corrente teórica que aborda a empresa sob a perspectiva dos recursos e das capacidades, ambos controlados por ela, popularmente conhecidos como Visão Baseada em Recursos da empresa (VBR). Em seguida, o tema Inteligência Competitiva é discutido, enfatizando alguns conceitos, estrutura (processo) e a sua importância para a tomada de decisão estratégica. Na quarta parte é analisado o sistema de gerenciamento estratégico da empresa proposto por Norton e Kaplan: o Balanced Scorecard (BSC). Por último, na quinta e última etapa, é desenvolvido um modelo teórico para representar uma visão sistêmica dos relacionamentos existentes entre os temas tratados por essa pesquisa.

Em termos gerais, espera-se com esta pesquisa contribuir um pouco mais para o entendimento sistêmico dos temas Vantagem Competitiva Sustentável (VCS), Visão Baseada em Recursos da empresa (VBR), Inteligência Competitiva (IC) e Balanced Scorecard (BSC), a partir da análise das relações informacionais existentes entre eles, como também, fornecer insights significativos para o desenvolvimento de futuras pesquisas sobre os temas em questão.

\section{Desenvolvimento Teórico}

\subsection{Vantagem Competitiva e o Desafio da Sustentabilidade}

Em termos conceituais, Barney e Clark (2007) têm abordado o tema da vantagem competitiva a partir da capacidade de uma empresa de criar maior valor econômico para o mercado consumidor em comparação com os seus competidores. Porter (1989), nesta mesma linha de raciocínio, postula que uma empresa obtém vantagem competitiva, sustentável ou não, quando ela consegue gerar valor agregado superior para o seu mercado consumidor (em comparação aos seus competidores) e garantir um retorno significativo para o capital investido, argumento também defendido por Hitt, Ireland e Hoskisson (2003).

Na tentativa de melhor definir o que seja vantagem competitiva, Barney e Clark (2007) ainda ressaltam alguns pontos que precisam ser observados. Primeiro, deve-se considerar a criação de valor a partir das diferenças perce- 
bidas e obtidas pelo mercado em relação aos produtos e serviços oferecidos pela empresa. Segundo, a visão de criação de valor deriva-se dos princípios fundamentais da economia, ressaltando a diferença entre valor percebido por parte dos consumidores e o custo econômico em relação aos produtos e/ ou serviços oferecidos pela empresa. Em terceiro lugar, a ênfase nos benefícios percebidos sugere a percepção da qualidade como um fator diferencial no processo de escolha dos consumidores. E, finalmente, a busca por maior valor implica em obter maior eficiência. Assim, uma empresa pode oferecer maior valor para o mercado consumidor de duas formas principais: aumentando os benefícios percebidos, mantendo os custos constantes ou oferecer um mesmo benefício a um custo menor (BARNEY; CLARK, 2007). Porter (1989) também compartilha dessa visão. Para Porter (1989), a vantagem competitiva surge quando uma empresa consegue criar valor para o seu mercado consumidor a partir da oferta de produtos e serviços com preços menores em relação aos competidores, desde que mantido os mesmos benefícios. O ideal dessa relação matemática, que envolve benefício no numerador e custo no denominador, é o aumento do benefício percebido com o produto oferecido a um custo menor, apesar de praticamente parecer muito difícil a uma primeira vista que se consiga tal relação.

Hitt et al. (2003), Barney e Clark (2007), por exemplo, tecem os seguintes comentários sobre vantagem competitiva:

A competitividade estratégica é alcançada quando uma empresa é bem-sucedida na formulação e implementação de uma estratégia que gere valor. Quando esta firma implementa a referida estratégia que outras não conseguem reproduzir ou acreditam que seja muito dispendioso imitála, ela terá, então, obtido uma vantagem competitiva sustentável (doravante denominada simplesmente de vantagem competitiva). Uma empresa terá assegurado uma vantagem competitiva somente quando os esforços de outras para imitar a sua estratégia tiverem cessado ou fracassado (HITT; IRELAND; HOSKISSON, 2003, p. 5).

Uma empresa possui vantagem competitiva quando é capaz de gerar maior valor econômico do que empresas rivais. Valor econômico é simplesmente a diferença entre os benefícios percebidos ganhos por um cliente que compra produtos ou serviços de uma empresa e o custo econômico total desses produtos e serviços. Portanto, o tamanho 
da vantagem competitiva de uma empresa é a diferença entre o valor econômico que ela consegue criar e o valor econômico que suas rivais conseguem criar (BARNEY; CLARK, 2007, p. 10).

Em relação ao problema de erosão de uma vantagem competitiva, pesquisas recentes têm demonstrado que o contexto competitivo (ou setor de atividade) afeta diretamente a sustentabilidade de uma vantagem competitiva conquistada. Hitt, Ireland e Hoskisson (2003, p. 213), por exemplo, afirmam que "em alguns ambientes a construção de uma vantagem competitiva sustentável pode ser mais provável do que em outros". Em seus estudos, os autores apontam que nos três tipos de mercado, a vantagem competitiva pode ter sua sustentabilidade afetada: quer seja no mercado de ciclo lento, de ciclo padrão ou de ciclo rápido. Em cada um deles, as forças competitivas se diferenciam em termos de intervenção ou não do governo e das ações e reações competitivas existentes entre os seus diversos competidores.

No mercado de ciclo lento, por exemplo, os autores afirmam que há uma forte intervenção governamental através de leis e regulamentações que protegem e/ou impedem a competição. Nesse tipo de mercado, verifica-se que as empresas conseguem manter preços mais elevados e vantagens competitivas sustentáveis por períodos de tempo maiores do que as empresas operantes nos demais tipos de mercado (ciclo padrão e rápido) já que elas contam com a proteção dos seus mercados. Essa situação ocorre porque normalmente o mercado é monopolizado por uma ou poucas empresas. Para os autores, produtos que estão em mercados de ciclo lento refletem fortemente posições de recursos protegidos em que as pressões competitivas não penetram prontamente nas fontes de competitividade estratégica de uma organização. Essa situação muitas vezes é chamada pelos economistas de monopólio (HITT; IRELAND; HOSKISSON, 2003).

Por outro lado, os mercados de ciclo padrão tendem a refletir moderadamente posições de recursos protegidos em que a interação competitiva penetra nas fontes de competitividade estratégica da empresa, mas como advertem Hitt, Ireland e Hoskisson (2003, p. 215), "com a melhoria da sua capacidade, as empresas podem ser capazes de sustentar uma vantagem competitiva". Para os autores, os mercados de ciclo padrão estão estreitamente associados com a abordagem de economia de organizações exemplificada no modelo de Cinco Forças de Porter, cujas estratégias são projetadas para 
atender mercados de alto volume ou de massa, focando-se na coordenação e no controle de mercado (HITT; IRELAND; HOSKISSON, 2003).

Finalmente, Hitt, Ireland e Hoskisson (2003) argumentam que em mercados de ciclo rápido uma vantagem competitiva não pode ser sustentada por muito tempo. Nesse tipo de ambiente, as empresas tentam ganhar vantagens competitivas temporárias transformando estrategicamente o mercado. D'Aveni (1995), por exemplo, argumenta que a tentativa de manter uma vantagem competitiva nesse tipo de mercado pode consumir recursos que deveriam ser utilizados para a próxima estratégia competitiva. Segundo esse autor (p. XXX), "a sustentação de uma vantagem competitiva é uma estratégia defensiva projetada para proteger o que a empresa possui. Na hipercompetição, a melhor defesa é, com freqüência, um ataque forte". Assim, em vez de planos de longo alcance e de vantagens competitivas duradouras, as empresas devem implementar uma sucessão de ataques estratégicos pequenos, normalmente fáceis de copiar, encadeando uma série de vantagens de curto prazo, que somadas proporcionam vantagens para a empresa no longo prazo. Dessa maneira, a sustentabilidade das vantagens competitivas é obtida por meio de uma série de ações replicadas, geralmente obedecendo a uma fase empreendedora de lançamento da estratégia, passando por um período de exploração e, por fim, por um período de contra-ataque em que a vantagem competitiva começa a se deteriorar. Mas antes que isso aconteça, a empresa já deve estar preparando uma nova estratégia que possibilite novas vantagens competitivas para a empresa (HITT; IRELAND; HOSKISSON, 2003; D’AVENI, 1995). Observe que a Figura 1 ilustra esse processo.

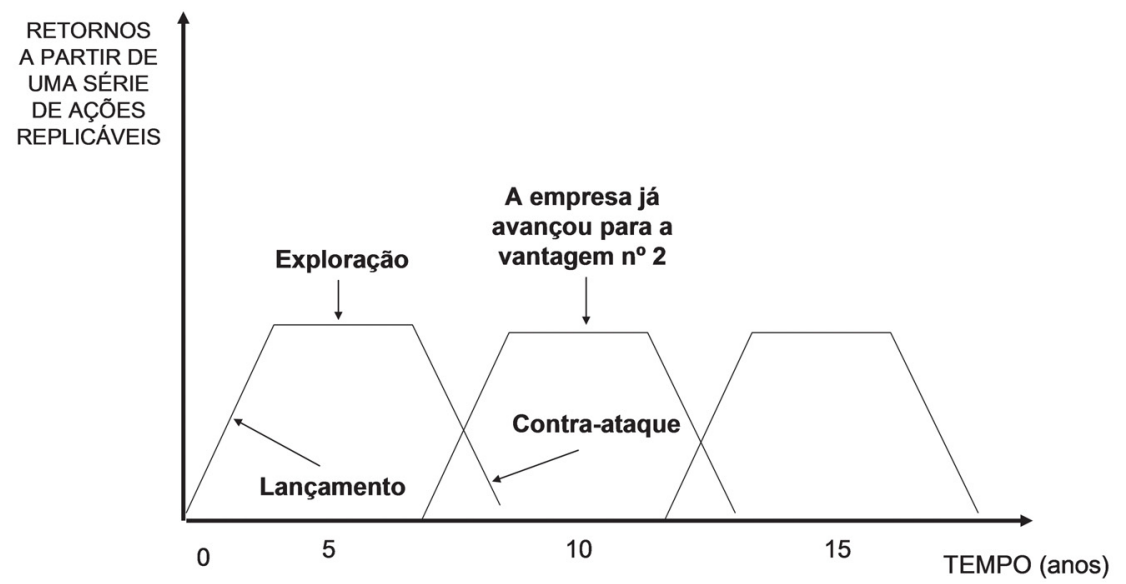

Figura 1: Obtendo vantagens temporárias para criar vantagens sustentáveis Fonte: Hitt, Ireland e Hoskisson (2003, p. 217) 
É consenso entre os autores pesquisados de que o principal fator que tem contribuído para a rápida deterioração das vantagens competitivas conquistadas é que os mercados de ciclo rápido estão cada vez mais difíceis de serem administrados devido à grande volatilidade e incerteza (complexidade e dinamicidade) dos seus elementos constituintes. Assim, conforme apontado por Hitt, Ireland e Hoskisson (2003) e D'Aveni (1995), percebe-se o surgimento de um novo paradigma de vantagem competitiva, no qual uma empresa se apodera da iniciativa de uma série de pequenos passos, criando uma série de contra-ataques antes que as suas vantagens competitivas conquistadas se deteriorem. Esses autores advertem, porém, que o contra-ataque pode levar a um processo de canibalização dos produtos e serviços da própria empresa.

Hitt, Ireland e Hoskisson (2003) ainda defendem a ideia de que o foco desse novo paradigma está na transformação competitiva, pois, segundo esses autores,

[...] uma empresa pode fazer disparar a competição em áreas como preço e qualidade somente até que o competidor predominante procure atingir outro nível de competição focalizada em fatores como velocidade, know-how ou inovação (HITT; IRELAND; HOSKISSON, 2003 p. 217).

Dessa forma, as empresas devem ser flexíveis estrategicamente se quiserem ser bem-sucedidas ao competir em mercados de ciclo rápido. Elas devem aprender e responder rapidamente à mudança tecnológica e às oportunidades de mercado, oferecendo rapidamente mais produtos novos, linhas de produtos mais amplas e constantes atualizações de seus produtos e serviços (HITT; IRELAND; HOSKISSON, 2003).

\subsection{Visão Baseada em Recursos da Empresa (VBR)}

O termo Visão Baseada em Recursos da empresa (VBR) foi inicialmente apresentado por Wernerfelf em um artigo publicado na Strategic Management Journal no ano de 1984. Pesquisadores como Barney (1991) e Peteraf (1993), entre outros, apresentaram contribuições importantes para o desenvolvimento e popularização da Teoria VBR nos meios acadêmicos e empresariais nos últimos anos. Atualmente, a VBR tem sido entendida na 
literatura como uma teoria econômica que sugere que o desempenho das empresas depende dos tipos de recursos e capacidades que elas controlam (Desempenho Empresarial $=f\{$ Recursos, Capacidades, Controle $\}$; no qual se entende que o desempenho empresarial é função dos recursos, capacidades e controle). De acordo com Barney e Hesterly (2007, p. 91), recursos devem ser entendidos como "os ativos tangíveis e intangíveis que uma empresa utiliza para criar e implementar suas estratégias" e capacidades como "um subgrupo de recursos que permitem que uma empresa tire vantagem de seus outros recursos".

Para explicar por que duas empresas operando em um mesmo setor apresentam resultados diferentes, Barney e Hesterly (2007) ressaltam duas suposições básicas sobre os recursos e capacidades que as empresas controlam: heterogeneidade da imobilidade dos recursos e capacidades. No primeiro caso, argumentam os autores, "empresas diferentes podem possuir conjuntos diferentes de recursos e capacidades, mesmo que estejam competindo em um mesmo setor" (BARNEY; HESTERLY, 2007, p. 65). A heterogeneidade de recursos significa que, para determinado ramo de atividade, algumas empresas podem ser mais competentes em realizar determinadas atividades do que outras (BARNEY; HESTERLY, 2007). No segundo caso, a questão central volta-se para o tempo em que essas diferenças existentes entre recursos e capacidades podem ser sustentadas pelas empresas. Isso pode ocorrer, segundo os autores, porque pode ser muito custoso para as empresas, sem certos recursos e capacidades, desenvolvê-los ou adquirilos. Dessa maneira, ao se considerar essas duas suposições juntas, pode-se explicar por que algumas empresas superam outras, mesmo que estejam todas competindo no mesmo setor, como argumentam Barney e Hesterly (2007, p. 65):

[...] se uma empresa possui recursos e capacidades valiosos que outras poucas empresas possuem, e se essas outras empresas consideram muito custoso imitar esses recursos e capacidades, a empresa que possui esses ativos tangíveis e intangíveis pode obter uma vantagem competitiva sustentável.

Para esses autores, recursos e capacidades podem ser categorizados em financeiros, físicos, humanos e organizacionais, conforme demonstrado pela Figura 2. 
Modelo VBR

(Recursos e Capacidades)

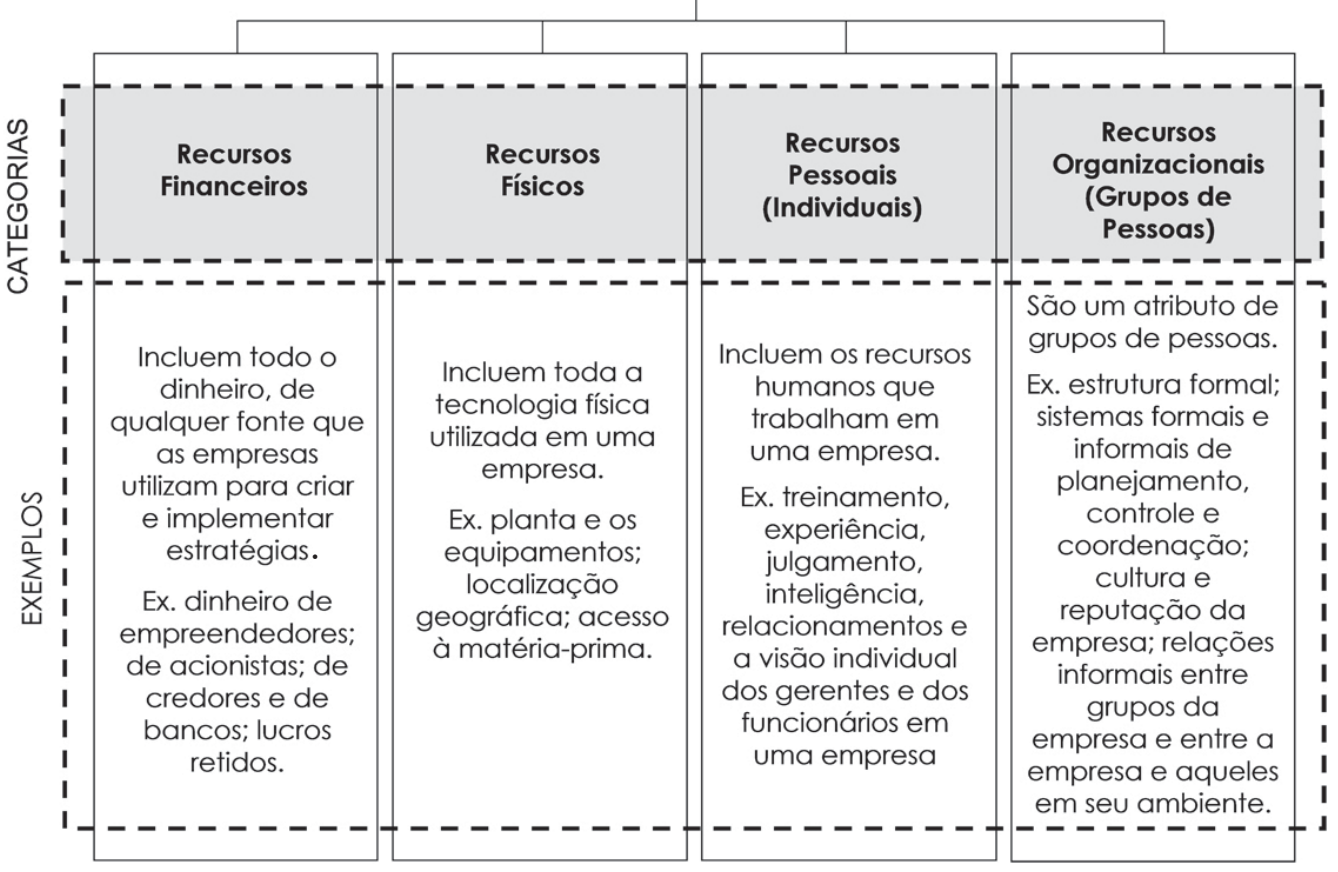

Figura 2: Recursos e capacidades empresariais

Fonte: Adaptada de Barney e Hesterly (2007, p. 65)

De acordo com a Figura 2, percebe-se que os recursos e as capacidades empresariais podem envolver tanto aspectos individuais como coletivos de uma empresa, alinhando-se aos seus recursos financeiros e físicos. Uma estrutura bastante similar ao demonstrado pelo VBR é o Balanced Scorecard (BSC), proposto por Kaplan e Norton (1997) para a análise do desempenho estratégico empresarial, o qual está apresentado na Seção 2.4 desta pesquisa.

\subsection{Inteligência Competitiva: monitorando o ambiente competitivo}

Para muitas empresas contemporâneas, a IC tem assumido papel de destaque, como atividade de suporte às atividades de administração estratégica, na medida em que disponibiliza informações estratégicas cada vez mais precisas, rápidas, confiáveis e oportunas sobre fatos, eventos, tendências e 
relacionamentos que acontecem no ambiente competitivo em que as empresas atuam. Orientada para o ambiente competitivo, a IC tem a missão de ajudar os altos executivos a reduzirem os riscos envolvidos nas decisões estratégicas a serem tomadas (OLIVEIRA; ALMEIDA; LACERDA, 2007).

Para Miller (2002, p. 31), por exemplo, uma das razões que justifica o emprego da inteligência na tomada de decisão é a de que "os gerentes conscientes de sua função não conseguem se manter a par das alternativas que o mercado apresenta, tantas são elas" e que "tomar as decisões adequadas para dar às suas empresas vantagem sobre as concorrentes é, para eles, um processo que exige um cuidadoso estudo das questões relevantes". Nesse sentido, dado o crescimento exponencial do volume de informações disponíveis no mercado e demandadas pelas empresas, a IC surge como uma possibilidade interessante de aperfeiçoamento contínuo do processo decisório conduzido pelos altos executivos empresariais. Assim, conforme argumenta Miller (2002, p. 31)

[...] gerentes conscientes reconhecem que as organizações competem com maior eficiência quando seus gerentes tomam decisões bem fundamentadas, a partir de um entendimento adequado do potencial de oportunidades e de riscos de um determinado negócio.

No atual contexto competitivo, a Inteligência Competitiva (IC) tem sido entendida na literatura como um processo ético e legal de coleta de dados e informações sobre o ambiente competitivo, os quais são transformados e disponibilizados, na forma de inteligência útil, aos responsáveis pela tomada de decisão estratégica (FULD, 1995; TYSON, 1998; PRESCOTT; MILLER, 2002). A Figura 3 apresenta as principais etapas do processo de IC e o seu relacionamento com o ambiente externo. 


\section{Estratégias Competitivas}

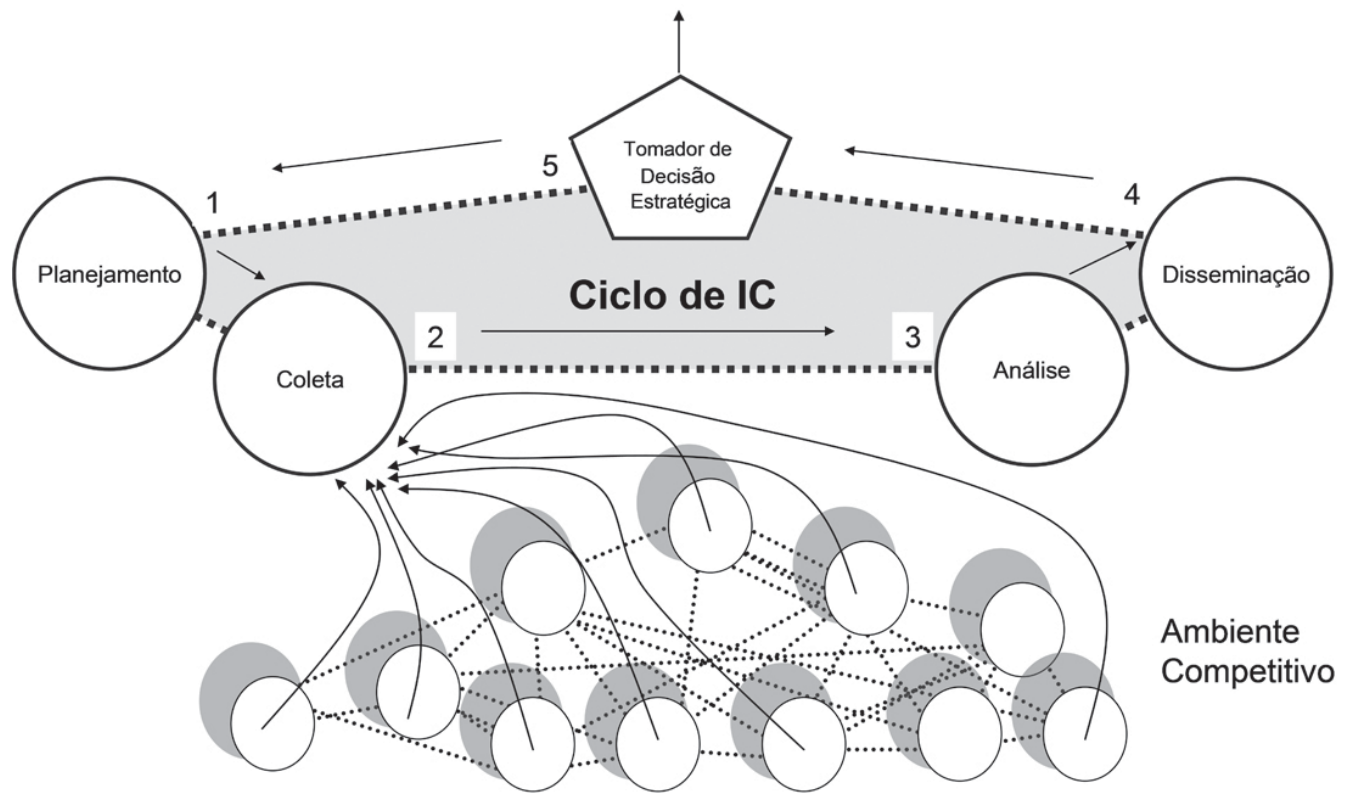

Figura 3: Visão sistêmica da função de Inteligência Competitiva Fonte: Elaborada pelos autores

De acordo com a Figura 3, percebe-se que o processo de IC tem início com o levantamento das necessidades de inteligência e a identificação dos respectivos usuários, denominada de etapa de planejamento. Em seguida, os profissionais de IC identificam e selecionam as fontes de dados e informações adequadas para o processo de coleta, o qual pode utilizar diversos tipos de fontes, sejam elas primárias e/ou secundárias. O Quadro 1 apresenta algumas das principais fontes de dados e informações internas e externas à empresa que podem ser utilizadas pelos profissionais de IC. 


\begin{tabular}{|l|l|}
\hline \multicolumn{1}{|c|}{ FONTES INTERNAS } & \multicolumn{1}{c|}{ FONTES EXTERNAS } \\
\hline 1. FUNCIONÁRIOS DA EMPRESA & 1. AGÊNCIAS DE PUBLICIDADE DA EMPRESA \\
2. ENGENHARIA & 2. BANCOS \\
3. FINANÇAS & 3. CONSULTORES \\
4. RECURSOS HUMANOS & 4. CLIENTES \\
5. CENTROS DE INFORMAÇÃO & 5. DISTRIBUIDORES \\
6. PRODUÇÃO & 6. IMPRENSA GERAL OU SETORIAL \\
7. MARKETING & 7. FABRICANTES DE EQUIPAMENTOS \\
8. SUPRIMENTOS & 8. ANALISTAS FINANCEIROS \\
9. RELAÇÕES PÚBLICAS & 9. GOVERNO \\
10. PESQUISA E DESENVOLVIMENTO & 10. SINDICATOS \\
11. VENDAS & 11. ADVOGADOS \\
& 12. ESPECIALISTAS EM PATENTES \\
& 13. EX-FUNCIONÁRIOS \\
& 14. FORNECEDORES \\
& 15. ASSOCIAÇÕES SETORIAIS \\
\hline
\end{tabular}

Quadro 1: Fontes internas e externas de informações competitivas Fonte: Gordon (2004, p. 230-232).

$\mathrm{Na}$ análise dos dados e informações, os profissionais de IC devem agir de maneira proativa e criativa, prospectando, analisando, comparando, fazendo projeções, analogias, enfim, tentando encontrar algum significado útil ou valor agregado aos dados e informações obtidos na fase anterior. Nessa etapa, os dados são transformados em informações que, por sua vez, são transformadas em produtos de inteligência. O Quadro 2 resume algumas das principais ferramentas (métodos e técnicas) de análise à disposição dos profissionais de IC na atualidade. 


\section{INSTRUMENTOS DE ANÁLISE}

Modelo de Cinco Forças de Porter.

Fatores Críticos de Sucesso.

Análise SWOT (Forças, Fraquezas, Ameaças e Oportunidades).

Balanced Scorecard (BSC).

Benchmarking.

Data Mining (Mineração de Dados).

Data Warehousing (Armazém de Dados).

Matriz de Crescimento.

Competências Essenciais (Core Competences).

Análise das citações de patentes.

Análise da Cadeia de Valor.

Custeio Baseado em Atividades (Custeio ABC).

Gerenciamento pelo Valor Econômico.

Quadro 2: Algumas técnicas e modelos analíticos para a IC

Fonte: Tarapanoff (2001, p. 167-300) e Miller (2002, p. 93-119)

Finalmente, a última fase refere-se ao processo de disseminação (ou distribuição) da inteligência produzida aos integrantes da alta cúpula da empresa. Essa transmissão pode ser oral, documentada ou digital e pode acontecer por meio de sumários executivos ou mapas de conhecimento, através de relatórios formais de pesquisa, reuniões de equipe, site interno da empresa (intranet), memorandos ou por outros meios tecnológicos ou não. Para Miller (2002, p. 38), "qualquer que seja o conteúdo ou formatação, no entanto, o essencial é que disseminem os resultados eficazmente" e que "entender de que maneira os responsáveis pelas decisões preferem que as informações lhes sejam repassadas certamente aumenta a integridade e a futura utilização do que é relatado". Dessa maneira, pode-se observar que, nesta fase do processo de IC, é de suma importância que os profissionais de inteligência tenham plena consciência de que as necessidades dos decisores estratégicos foram satisfeitas em sua plenitude, para que o sistema traga os resultados desejados, ou seja: decisões estratégicas eficazes e orientadas para a obtenção de vantagens competitivas sustentáveis. 


\subsection{Balanced Scorecard (BSC)}

Balanced Scorecard (BSC) é um sistema gerencial estratégico que alinha e preserva as medidas financeiras tradicionais, até certo ponto inadequadas para orientar e avaliar a trajetória da empresa especialmente neste contexto competitivo baseado na informação, com medidas não financeiras orientadas para a geração de valor futuro através do investimento em clientes, fornecedores, funcionários, processos, tecnologia e inovação (KAPLAN; NORTON, 1997).

Em geral, entende-se BSC como um sistema de gestão estratégica utilizado pelas empresas para administrar a estratégia em longo prazo, pois, segundo Kaplan e Norton (1997, p. 9-10), esse sistema permite aos gerentes e executivos "esclarecer e traduzir a visão e a estratégia; comunicar e associar objetivos e medidas estratégicas; planejar, estabelecer metas e alinhar iniciativas estratégicas; melhorar o feedback e o aprendizado estratégico". A Figura 4 apresenta a estrutura do BSC utilizada para a tradução da estratégia em termos operacionais.

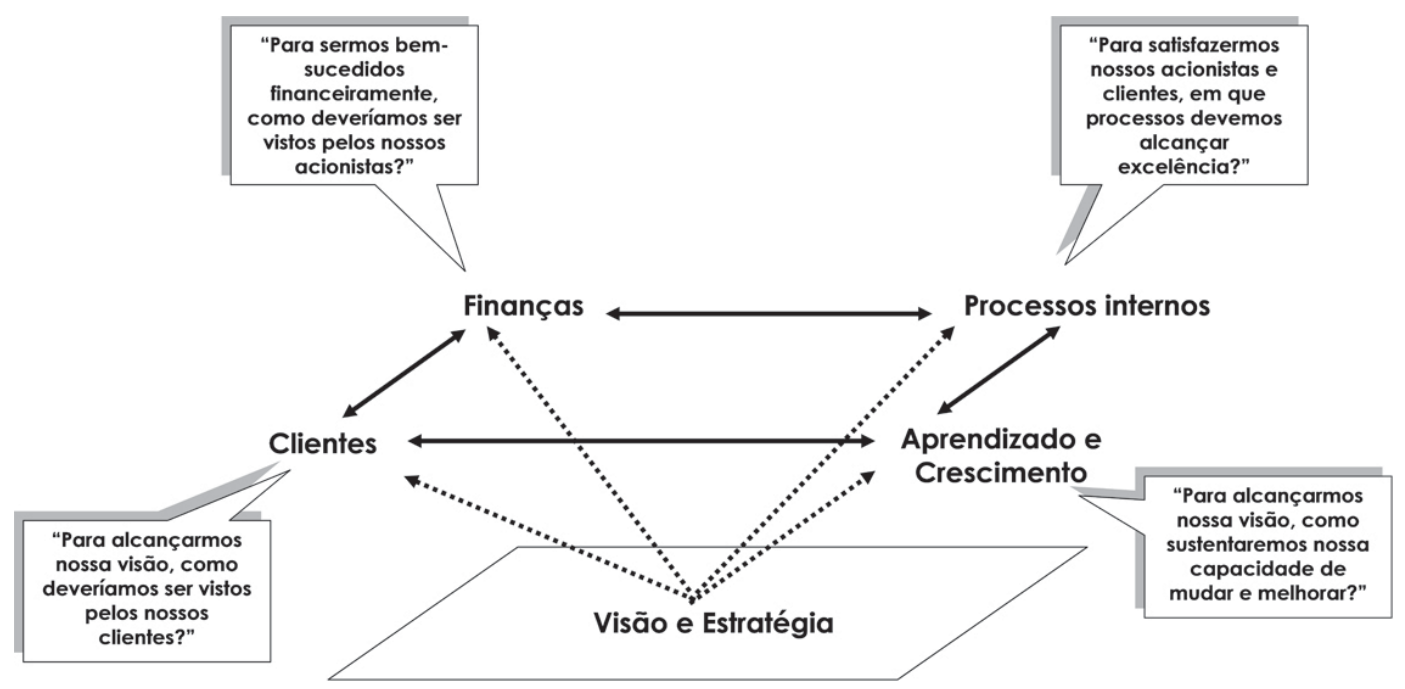

Figura 4: Estrutura do Balanced Scorecard para a tradução da estratégia de negócios em termos operacionais Fonte: Adaptada de Kaplan e Norton (1997, p. 10) 
Segundo Kaplan e Norton (1997), o processo do scorecard tem início com o trabalho de equipe da alta administração para traduzir a estratégia de sua unidade de negócios em objetivos estratégicos específicos, como por exemplo, metas financeiras, que devem priorizar a receita e o crescimento de mercado, a lucratividade ou a geração de fluxo de caixa; metas dos clientes, em que a equipe gerencial deve ser clara em relação aos segmentos de clientes e mercados pelos quais a empresa está disposta a competir; identificar objetivos e medidas para os processos internos, cujos gestores devem se concentrar nos processos mais críticos para a obtenção de um desempenho superior para clientes e acionistas e, finalmente, são identificadas metas de aprendizado e ressaltada a importância do crescimento empresarial. Nesse ponto, argumentam os autores, a empresa expõe os motivos para investimentos significativos na reciclagem de funcionários, na tecnologia e nos sistemas de informações, como também, na melhoria dos procedimentos organizacionais. Com esses investimentos, espera-se que as pessoas sejam capazes de produzir inovações e melhorias importantes para os processos internos de negócios, para os clientes e, por fim, para os acionistas (KAPLAN; NORTON, 1997).

É importante destacar que o scorecard desenvolvido pelo grupo de altos executivos é o resultado de um modelo consensual da empresa inteira, em que cada executivo prestou a sua contribuição. Isso é importante, já que desenvolve um espírito de participação coletiva, motiva os executivos e distribui responsabilidades pelo sucesso do BSC. Dessa forma, segundo argumentam Kaplan e Norton (1997, p. 13)

[...] os objetivos do scorecard torna-se uma responsabilidade funcional conjunta do grupo executivo, e passa a funcionar como ponto de referência para uma série de importantes processos gerenciais baseados em equipe.

Assim, o sistema do scorecard serve para desenvolver o trabalho em equipe entre os altos executivos, independentemente de suas experiências de trabalho anteriores ou de suas habilidades funcionais (KAPLAN; NORTON, 1997).

Eles ainda defendem que as empresas da era da informação serão bemsucedidas investindo e gerenciando seus ativos intelectuais, pois, segundo Kaplan e Norton (1997, p. 3), "o ambiente da era da informação, tanto para as organizações do setor de produção quanto para as do setor de serviços, exige novas capacidades para assegurar o sucesso competitivo" e que "a capacidade de mobilização e exploração dos ativos tangíveis ou invisíveis tor- 
nou-se muito mais decisiva do que investir e gerenciar ativos físicos tangíveis". O Quadro 3 apresenta os principais benefícios proporcionados pelos ativos intangíveis às empresas na era da informação.

\section{Os ativos intangíveis permitem que as empresas...}

1. Desenvolvam relacionamentos que conservem a fidelidade dos clientes existentes e permitam que novos segmentos de clientes e áreas de mercado sejam atendidos com eficácia e eficiência.

2. Lance produtos e serviços inovadores desejados por seus clientes-alvo.

3. Produza bens e serviços customizados de alta qualidade a preços baixos e com ciclos de produção mais curtos.

4. Mobilize as habilidades e a motivação dos funcionários para a melhoria contínua de processos, qualidade e os tempos de resposta.

5. Utilize tecnologia da informação, bancos de dados e sistemas.

Quadro 3: Benefícios dos ativos intangíveis para as empresas na era da informação Fonte: Kaplan e Norton (1997, p. 3-4)

Finalmente, ainda nas palavras de Kaplan e Norton (1997, p. 20), as empresas podem utilizar o BSC para:

1. Esclarecer e obter consenso em relação à estratégia.

2. Comunicar a estratégia a toda a empresa.

3. Alinhar as metas departamentais e pessoais à estratégia.

4. Associar os objetivos estratégicos com metas de longo prazo e orçamentos atuais.

5. Identificar e alinhar as iniciativas estratégicas.

6. Realizar revisões estratégicas periódicas e sistemáticas.

7. Obter feedback para aprofundar o conhecimento da estratégia e aperfeiçoá-la.

\subsection{Integrando a IC ao BSC para a obtenção de VCS no contexto da VBR: uma abordagem informacional}

Conforme explicitado anteriormente, o ambiente competitivo está em crescente processo de transformação, o que tem proporcionado o aumento de incertezas e colocado em risco a sobrevivência e o crescimento das orga- 
nizações nos mercados em que atuam ao longo do tempo. Manter-se constantemente atualizadas sobre os movimentos das variáveis ambientais parece ser um pré-requisito para um ajuste rápido e eficaz, por meio de estratégias rápidas e inteligentes, para as ameaças e oportunidades impostas pelos ambientes competitivos. Nessa perspectiva, temas como Inteligência Competitiva, Balanced Scorecard e Visão Baseada em Recursos da empresa assumem relevância, especialmente por que ajudam os altos executivos a monitorarem os seus ambientes de negócios, mensurarem o valor das estratégias formuladas e implementadas, como também, identificar as forças e fraquezas internas através da identificação e análise dos recursos e capacidades controlados pelas empresas. A Figura 4 apresenta um modelo sistêmico para representar as relações de dependência informacional entre essas importantes atividades ou teorias para as empresas contemporâneas.

De acordo com a Figura 5 percebe-se que a busca por vantagens competitivas sustentáveis começa com a identificação da visão e a estratégia atual utilizada pela empresa, as quais servem de base para o planejamento de um processo de IC (1). Nesse ponto é importante destacar a importância do alinhamento estratégico entre os departamentos de IC e de Administração Estratégica da empresa. Em seguida, os profissionais de IC identificam e selecionam as fontes de informações apropriadas para a coleta de dados $e$ informações sobre o ambiente competitivo (2) e (3). Os dados e informações coletados são validados e armazenados em grandes bancos de dados, os quais podem ser categorizados em diversas formas possíveis, conforme a conveniência e aplicação dos mesmos na tomada de decisão. Para a produção da inteligência (4), os dados e informações armazenados são processados e avaliados. Nesta etapa, pode-se utilizar softwares especializados e métodos científicos apropriados, conforme aqueles listados no Quadro 2 da Seção 2.3. Criado os produtos de inteligência, em seguida eles são disponibilizados, de forma oral, escrita ou digital, aos responsáveis pela tomada de decisão estratégica (5) para o desenvolvimento de estratégias competitivas orientadas para a consecução de vantagens competitivas sustentáveis (6). Para medir o desempenho das estratégias formuladas e implementadas, os altos executivos podem utilizar o BSC que considera cinco perspectivas relevantes: a financeira, a dos clientes, a dos processos internos e a do aprendizado e crescimento (7). Cada uma dessas perspectivas é traduzida em objetivos, metas e indicadores de desempenho que são monitorados sistematicamente em todos os níveis empresariais. Englobando 
os processos de IC e do BSC, a VBR atua como elemento-chave na determinação dos recursos e capacidades controlados pela empresa que podem ser considerados como fontes de vantagens competitivas sustentáveis (8), desde que atendam aos critérios de valor, raridade, imitabilidade e organização apresentado por Barney e Hesterly (2007). Dessa maneira, para ter vantagens competitivas sustentáveis, os recursos e as capacidades mantidos pelas empresas devem ser únicos e custosos de serem imitados pelos concorrentes, as informações estratégicas, disponibilizadas pelos profissionais de IC, devem permitir que os altos executivos formulem e implementem estratégias inteligentes orientadas para a neutralização de ameaças (mercado competidor) e para a obtenção de novas oportunidades de negócios (mercado consumidor) e que as mesmas possam ser gerenciadas e aplicadas por todos os indivíduos da empresa (BSC).

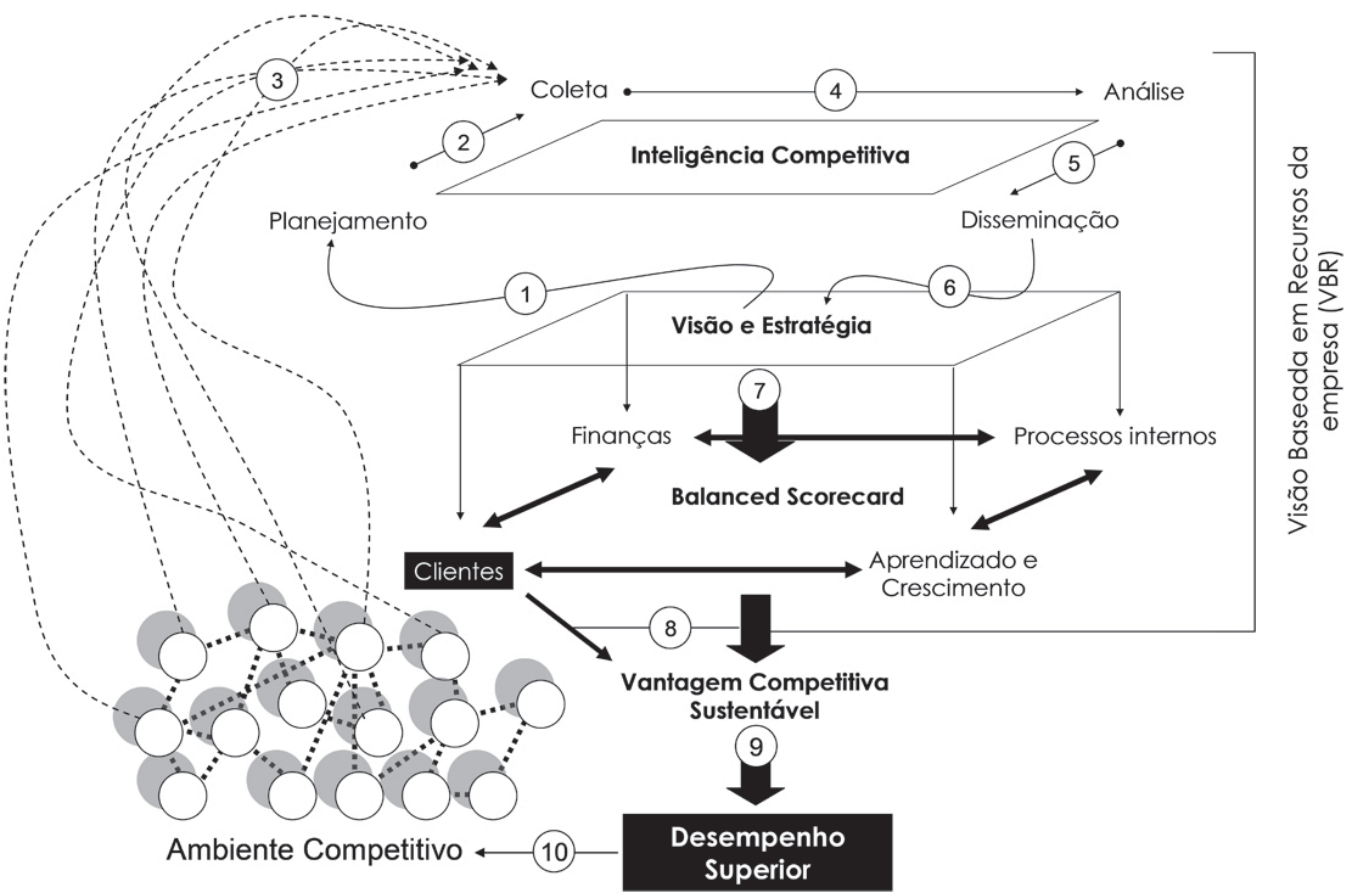

Figura 5: Visão integrada dos processos de Inteligência Competitiva e Balanced Scorecard no contexto da Visão Baseada em Recursos da empresa

Fonte: Elaborada pelos autores 


\section{Considerações Finais e Recomendações para Futuras Pesquisas}

Este artigo analisou o relacionamento sistêmico entre três importantes temas para o desempenho empresarial neste novo modelo de competição baseado na informação e no conhecimento: Visão Baseada em Recursos da empresa (VBR); Inteligência Competitiva (IC) e Balanced Scorecard (BSC). Em síntese, a partir da pesquisa bibliográfica realizada, pode-se observar que:

a) A sustentabilidade de uma vantagem competitiva conquistada depende do tipo de ambiente (ciclo lento, ciclo padrão e ciclo rápido) em que a empresa está inserida (D’AVENI, 1995; HITT; IRELAND; HOSKISSON, 2003).

b) $\mathrm{O}$ ambiente, na perspectiva da VBR, não é fator determinante para o desempenho de uma empresa. Para os autores dessa corrente teórica, dentre eles pode-se citar Wernerfelt (1984), Barney (1991) e Barney e Hesterly (2007), o desempenho de uma empresa é variável dependente dos recursos e capacidades controlados por ela e que diferentes desempenhos empresariais podem ser explicados pelas suposições de heterogeneidade e imobilidade dos recursos e capacidades.

c) Para manterem-se continuamente atualizadas em relação às mudanças do ambiente competitivo e à frente dos concorrentes, as empresas precisam ser capazes de estruturarem sistemas ou processos de inteligência competitiva capazes de fornecer informações estratégicas (produtos de inteligência) rápidas, precisas, confiáveis e oportunas aos responsáveis pela tomada de decisão estratégica (FULD, 1995; MILLER, 2002).

d) Que o BSC tem papel fundamental na integração dos temas propostos por esta pesquisa na medida em que avalia a eficiência e a eficácia das estratégias implementadas, o qual é conduzido pela alta administração, levando em conta quatro perspectivas importantes para a empresa: finanças, clientes, processos internos 
e aprendizagem e crescimento. Assim, ao responder às perguntas "para sermos bem-sucedidos financeiramente, como deveríamos ser vistos pelos nossos acionistas? Para alcançarmos nossa visão, como deveríamos ser vistos pelos nossos clientes? Para satisfazermos nossos acionistas e clientes, em que processos de negócios devemos alcançar a excelência? Para alcançarmos nossa visão, como sustentaremos nossa capacidade de mudar e melhorar?" Esse sistema de gerenciamento estratégico promove as condições necessárias para o alinhamento estratégico entre os diversos recursos e capacidades controlados pela empresa.

e) O modelo teórico proposto pode ajudar os estrategistas a delinearem estratégias mais eficazes e orientadas para a obtenção de vantagens competitivas sustentáveis para as suas organizações nos mercados em que atuam na medida em que integra o fluxo informacional entre os ambientes internos e externos (ambiente competitivo) e demonstra, sistêmica e estrategicamente, como três importantes processos para a gestão estratégica na atualidade podem ser combinados para a obtenção de vantagens competitivas sustentáveis: VBR, IC e BSC. Assim, os estrategistas podem identificar as forças e fraquezas da organização, acompanhar instantaneamente os movimentos estratégicos dos concorrentes no ambiente de negócios e verificar o desempenho das estratégias implementadas praticamente em tempo real, tomando ações corretivas sempre que necessário.

Para futuras pesquisas recomenda-se o desenvolvimento de estudos empíricos em amostras significativas de empresas que utilizem essas ferramentas na tomada de decisão estratégica, como também, o uso de técnicas estatísticas apropriadas para mensurar as relações de dependências informacionais existentes entre os temas abordados por essa pesquisa, conforme apresentado na Figura 5, como também, recomenda-se a utilização de software específico, como o UCINET 6,0 for Windows, por exemplo, para representar graficamente tais relações de dependência informacional. 


\section{Resource-Based View of the Firm, Competitive Intelligence and Balanced Scorecard: in search of Sustainable Competitive Advantage}

\section{Abstract}

This article presents a theoretical model that integrates three important themes related to the strategy theory at present - Resource Based View (RBV), Competitive Intelligence (CI) and Balanced Scorecard (BSC) -, in terms of strategic formulation and implementation. These themes have been presented in publications of researchers in the field of strategy reaching the dimensions of concept and process. On one side the RBV inside out as the emphasis back us to assess what we are and what we have for improving conditions for achieving superior results. The model CI refers to the condition of connection of outside in and inside out for the position at the interface of organizations. The BSC guides the condition to meet a few dimensions and processes. It also discusses how this integration can help companies gain competitive advantage in markets that operate over the time.

Key words: Resource-Based View. Competitive Intelligence. Balanced Scorecard. Integrated Approach.

Agradecimentos

Os autores agradecem ao Centro de Pós-graduação e Pesquisas em Administração (CEPEAD) da Universidade Federal de Minas Gerais, especialmente aos funcionários e pesquisadores da linha de pesquisa Mercadologia e Administração Estratégica e do Núcleo de Pesquisa, Ensino em Marketing e Estratégia de Operações (NUME) pelo apoio e infraestrutura disponibilizados, sem os quais não seria possível a realização deste artigo.

\section{Referências}

BARNEY, Jay B. Firm resources and sustained competitive advantage. Journal of Management, v. 17, n. 1, p. 99-120, mar. 1991.

BARNEY, Jay B. Is the Resource-Based "View" a useful perspective for strategic management research? Yes. Academy of Management Review, v. 26, n. 1, p. 41-56, jan. 2001. 
BARNEY, Jay B.; CLARK, Delwyn N. Resource-Based Theory: Creating and Sustaining Competitive Advantage. NY: Oxford University, 2007.

BARNEY, Jay; HESTERLY, W. S. Administração Estratégica e Vantagem Competitiva. São Paulo: Pearson Prentice Hall, 2007.

D'AVENI, Richard. Hipercompetição. Rio de Janeiro: Campus, 1995.

FULD, L. M. The new competitor intelligence: the complete resource for finding, analyzing, and using information about your competitors. New York: John Wiley \& Sons, 1995.

GORDON, J. H. De olho na concorrência: como vencer a batalha por mercado e clientes. São Paulo: Futura, 2004.

HITT, Michael A.; IRELAND, R. Duane; HOSKISSON, Robert E. Administração Estratégica. São Paulo: Bookman, 2003.

KAPLAN, Robert S.; NORTON, David P. A Estratégia em Ação: Balanced Scorecard. Rio de Janeiro: Campus, 1997.

MILLER, J. O Milênio da Inteligência Competitiva. Porto Alegre: Bookman, 2002.

OLIVEIRA, P. H.; ALMEIDA, P. P.; LACERDA, J. M. Práticas de inteligência competitiva no setor varejista de Belo Horizonte: um estudo exploratório. In: 20 Congresso Internacional de Administração, 2007, Ponta Grossa: UEPG, 2007.

PETERAF, M. The cornerstones of competitive advantage: a resource-based view. Strategic Management Journal. v. 14, p. 179-191, 1993.

PORTER, Michael E. Competitive strategy: techniques for analyzing industries and competitors. New York: Free Press, 1980.

Vantagem competitiva: criando e sustentando um desempenho superior. Rio de Janeiro: Campus, 1989.

PRAHALAD, C. K.; HAMEL, Gary. The core competence of the corporation. Harvard Business Review, v. 68, n. 3, p. 79-91, may/jun., 1990. 
PRESCOTT, J. E. Inteligência competitiva - Lições das trincheiras. In: PRESCOTT, J. E.; MILLER, S. H. Inteligência Competitiva na Prática. Rio de Janeiro: Editora Campus, 2002. p. 17-38.

TARAPANOFF, Kira (Org). Inteligência Organizacional e Competitiva. Editora Universidade de Brasília, Brasília, 2001.

TYSON, K. W. M. The complete guide to competitive intelligence. Lisle (Chicago): Kirk Tyson International, 1998.

WERNERFELT, B. A resource-based view of the firm. Strategic Management Journal, v. 5, n. 2, p. 171-180, apr./june, 1984. 